\title{
Outcomes of adult heroin users v. abstinent users four years after presenting for heroin detoxification treatment
}

\author{
Z Khan, ${ }^{1} \mathrm{MB}$ ChB, FCPsych, MMed (Psych); K J Cloete, ${ }^{1} \mathrm{PhD} ; \mathbf{J}$ Harvey, ${ }^{2} \mathrm{PhD} ; \mathbf{L}$ Weich, ${ }^{1} \mathrm{MB} \mathrm{ChB}, \mathrm{MRCPsych}, \mathrm{FCPsych}$ \\ ${ }^{1}$ Department of Psychiatry, Faculty of Medicine and Health Sciences, Stellenbosch University, Tygerberg, Cape Town, South Africa \\ ${ }^{2}$ Centre for Statistical Consultation, Stellenbosch University, Cape Town, South Africa
}

Corresponding author: L Weich (lizew@sun.ac.za)

Background. There are no studies in South Africa (SA) on the outcomes following detoxification and psychosocial rehabilitation of heroindependent patients.

Objective. To compare the demographic, clinical, forensic and treatment data of active heroin users v. users who were abstinent at the time of interview 4 years after attending the Opioid Detoxification Unit at Stikland Hospital in the Western Cape Province, SA.

Method. Participants included patients above the age of 16 years who had been admitted to the Opioid Detoxification Unit at Stikland Hospital for heroin detoxification between July 2006 and June 2007. Participants were individually interviewed (either in person or telephonically) using a structured self-report questionnaire to collect demographic, clinical, forensic and treatment data 4 years following heroin detoxification treatment at this unit.

Results. Of the participants, $60 \%$ were abstinent and a large portion (34\%) attributed this to social support. Furthermore, there was a significant $(p=0.04)$ difference in the longest period of abstinence between the past user group and active users, with more participants in the past user group being abstinent for 18 months or longer $(n=24,57 \%)$ than in the active users group $(n=8,29 \%)$. Active users $(n=18,64 \%)$ had significantly $(p=0.03)$ more legal problems than abstinent users $(n=14,33 \%)$. Most participants $(n=38,54 \%)$ relapsed within 3 months after index detoxification and rehabilitation.

Conclusion. Active users had more legal problems than abstinent users, with social support structures playing a pivotal role in abstinence. Future research should assess the impact of interventions such as post-discharge social support programmes on criminality and heroin use in those that relapse following treatment. 


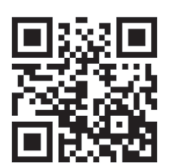

Heroin is the fourth most frequently abused substance in patients presenting for substance abuse treatment in South Africa (SA), with a recorded prevalence of $7.9 \% .{ }^{[1]}$ In the Western Cape Province, heroin is the main illicit opioid abused, with a trend towards increased use. Statistics from the SA Community Epidemiology Network on Drug Use project showed a 15\% increase in patients presenting for heroin treatment in the Western Cape between 1996 and $2012 .{ }^{[2]}$

Opioid use disorders are medically treated by placing patients either on a maintenance substitution opioid to reduce harm and illicit opioid use, or by detoxifying patients and implementing relapse prevention strategies. Opioid substitution treatment has the best outcomes and is therefore the treatment of choice in most countries. ${ }^{[3]}$ In SA, however, opioid use disorder is mainly treated by medical detoxification followed by psychosocial rehabilitation to prevent relapse.

The Opioid Detoxification Unit at Stikland Hospital in Cape Town Western Cape, is currently the only state-run, purpose-built facility in SA that the authors are aware of, where opioid-dependent patients are assessed, detoxified and treated for medical comorbidity. The unit has ten beds and is funded by the Western Cape Provincial Department of Health. Patients are referred from a rehabilitation agency and admitted for an average period of 1 week. They are medicated with an individualised dose of either buprenorphine/ naloxone or methadone, which is calculated and titrated against objectively rated withdrawal symptoms and gradually tapered off Besides detoxification treatment at the unit, patients are also offered privately funded substitution treatment if they are suitable candidates, willing and able to cover treatment costs. Detoxification is followed by either an in- or outpatient psychosocial rehabilitation programme provided by one of the social welfare-funded rehabilitation centres.

In developed countries, many large prospective cohort studies have reported on outcomes following opioid dependence treatment. These include the Drug Abuse Reporting Programme (DARP), Treatment Outcomes Prospective Study (TOPS), and Drug Abuse Treatment Outcomes Studies (DATOS) in the United States, ${ }^{[4]}$ the National Treatment Outcomes Research Study (NTORS) in the United Kingdom, ${ }^{[5]}$ the Australian Treatment Outcome Study in Australia, ${ }^{[6]}$ and the Amsterdam Cohort in the Netherlands. ${ }^{[7]}$ These studies showed that length of treatment predicts outcome, with treatment periods of $>3$ months showing higher rates and longer periods of abstinence. Furthermore, opioid substitution and community-based treatment were found to be effective in reducing drug use and criminal behaviour. As oral opioid substitution rather than opioid detoxification therapy is becoming the standard treatment of choice in most countries, most of the recent international studies include outcomes following opioid substitution therapy. ${ }^{[4-6]}$ However, a study by Gandhi et al. ${ }^{[8]}$ on the short-term outcomes of a 3-day ambulatory opioid detoxification programme reported a reduction in the severity of dependence for some younger heroin users who may not yet be ready to engage in long-term abstinence-oriented or opioid substitution treatments.

There are no studies on the clinical, social or forensic outcomes following detoxification and psychosocial rehabilitation of heroindependent patients treated at the Opioid Detoxification Unit, nor are there studies comparing long-term clinical, social and forensic outcomes for active heroin users v. users who managed to become abstinent following treatment. Additionally, as a developing country, SA is faced with numerous challenges such as high unemployment rates and very limited social welfare grants, and outcomes in this setting may therefore not reflect findings from international reports. Furthermore, there are no state-funded methadone or buprenorphine substitution programmes in SA where a strong emphasis is placed on total abstinence as the only successful treatment option for patients with heroin use disorders.

\section{Objective}

The objective was to assess the outcomes of heroin-dependent patients 4 years after detoxification at the Opioid Detoxification Unit, by comparing the demographic, forensic, clinical and treatment data between patients with heroin use disorders who were actively using at the time of investigation and those who had been abstinent for at least the previous 4 weeks at the time of investigation.

\section{Method \\ Study design and setting}

This was a retrospective cohort study conducted at the Opioid Detoxification Unit from October 2010 to July 2011.

\section{Definitions}

Legal problems included self-reported arrests without charges, pending criminal charges, convictions and criminal activities that were not reported to the police or correctional services. The index episode was defined as the first admission for heroin detoxification at the Opioid Detoxification Unit. A readmission was defined as a readmission after the index episode to either the Opioid Detoxification Unit or any other substance treatment programme for heroin use disorder. Users who were considered abstinent at the time of interview were defined as not having used heroin for at least the previous 4 weeks. Support structures included family, friends and various organisations such as day-patient programmes and aftercare support groups run by substance treatment programmes, self-help support groups such as Narcotics Anonymous, and support from and involvement with religious institutions.

\section{Study population}

The study population included all patients aged 16 years or older admitted to the Opioid Detoxification Unit specifically for heroin detoxification during the period June 2006 to July 2007. Patients were included regardless of whether they completed or terminated the programme. The unit does not admit patients younger than 16 years old, and patients admitted for detoxification from opioids other than heroin were excluded from the study.

\section{Data collection}

Participants were interviewed 4 years after attending the Opioid Detoxification Unit either: (i) telephonically; (ii) in person at their local community health centre; or (iii) in person at the Opioid Detoxification Unit if readmitted during the study period. Participants were interviewed using a structured, interviewer-administered questionnaire to collect demographic, forensic, clinical and treatment data.

Demographic data included age, gender, education, employment, length of employment and marital status after treatment. Forensic 


\section{ARTICLE}
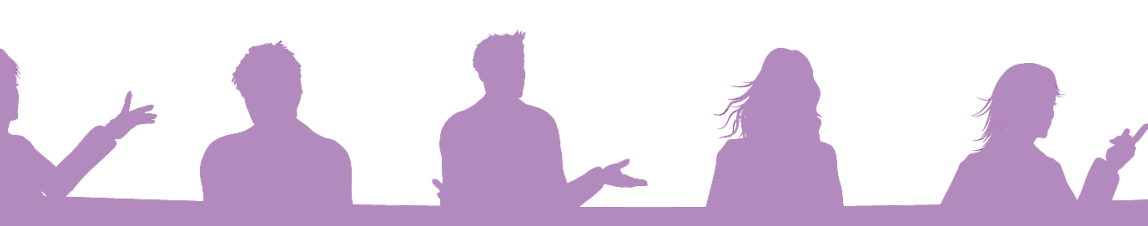

data included variables as defined under legal problems above. Clinical data included frequency of heroin use per day, mode of administration, all health problems, psychiatric problems and type of psychiatric disorders during the 4 years after treatment. Treatment data included admission details, details of treatment during admission, abstinence after treatment, rehabilitation details and details pertaining to social support structures.

\section{Data analyses}

The data were captured using Windows Excel software (Microsoft, USA) and analysed using Statistica version 10 (StatSoft Inc., USA).

Continuous variables such as age were summarised using means and standard deviations (SDs). Absolute and relative frequencies were calculated for all categorical variables. Pearson's $\chi^{2}$ or the $t$-test for independent samples was used to compare categorical variables for active v. abstinent users. In cases where low expected frequencies were observed, the Fisher's exact test was used to confirm findings. Contingency tables were used to show differences in frequencies for categorical variables between active and abstinent users.

Significance was set at $p<0.05$, while 95\% confidence intervals (CIs) were used to describe the estimation of unknown parameters.

\section{Ethical considerations}

Ethical approval was obtained from the Health Research Ethics Committee at Stellenbosch University. Prior to telephonic interview, informed consent was obtained from each participant after telephonically explaining the consent form to them in their preferred language. In the case of face-toface interviews, participants provided written informed consent using the aforementioned form. Each participant was assigned a study number to ensure anonymity and preserve confidentiality. The data were kept confidential in a password-protected file on a computer used only by the investigator.

\section{Results \\ Participants}

The study population included 189 participants and complete data were collected for $70(37 \%)$ respondents. The following patients were not included in the final sample:
4 who died in the last 4 years, 23 who refused to participate, 23 who were untraceable due to irregular contact with their families, and 69 who were not contactable on their recorded telephone numbers.

Most participants $(n=42,60 \%)$ reported being abstinent from heroin at the time of investigation, while 26 (37\%) reported being completely abstinent since index admission.

Over one-third of participants $(n=24,34 \%)$ attributed abstinence to social support structures, while 15 (21\%) attributed abstinence to self-funded oral substitution pharmacotherapy. The number of treatment episodes was not significantly associated with better outcomes $(p=0.55)$.

\section{Demographic data}

There was no significant difference in age, gender, education, employment status, length of employment or marital status between active users and users who were abstinent at the time of interview (Table 1). The mean (SD) age of the entire group was 29.1 (5.8) years (95\% CI 27.74 - 30.49) years. Most participants in both groups were single and male. The users who were not actively using at the time of interview were more likely to have a Grade 12 level of education, while active users were more likely to have a Grade 10 level of education, but this finding was not statistically significant $(p=0.12$ ). Although there was a greater percentage of abstinent users who had been employed for 3 - 5 months $(n=12,52 \%)$ compared with active users $(n=4,40 \%)$, this finding was not statistically significant $(p=0.89)$.

\section{Forensic data}

There was a significant $(p=0.03)$ difference in the number of legal problems since index admission between the groups, with more participants in the active users group $(n=18$,

Table 1. Demographic data of active heroin users v. abstinent users 4 years after admission for heroin detoxification at the Opiod Detoxification Unit at Stikland Hospital

\begin{tabular}{|c|c|c|c|c|c|}
\hline \multirow{3}{*}{ Age, years (mean (SD), 95\% CI) } & \multicolumn{2}{|c|}{ Active users } & \multicolumn{2}{|c|}{ Abstinent users } & \multirow{3}{*}{$\begin{array}{l}\boldsymbol{p} \text {-value } \\
0.22\end{array}$} \\
\hline & \multicolumn{2}{|c|}{$28(5.8,26.72-29.42)$} & \multicolumn{2}{|c|}{$30(3.5,27.69-91.33)$} & \\
\hline & $n$ & $\%$ & $n$ & $\%$ & \\
\hline Gender & & & & & 0.81 \\
\hline Male & 22 & 79 & 32 & 76 & \\
\hline Female & 6 & 21 & 10 & 24 & \\
\hline Education & & & & & 0.12 \\
\hline Grade 9 & 2 & 7 & 3 & 7 & \\
\hline Grade 10 & 12 & 43 & 8 & 19 & \\
\hline Grade 11 & 8 & 29 & 10 & 24 & \\
\hline Grade 12 & 4 & 14 & 13 & 31 & \\
\hline $\begin{array}{l}\text { Tertiary level (university or } \\
\text { college) }\end{array}$ & 2 & 7 & 8 & 19 & \\
\hline Employment & & & & & 0.14 \\
\hline Yes & 10 & 36 & 23 & 55 & \\
\hline No & 18 & 64 & 19 & 45 & \\
\hline Length of employment, months & & & & & 0.89 \\
\hline$<3$ & 2 & 20 & 4 & 17 & \\
\hline $3-5$ & 4 & 40 & 12 & 52 & \\
\hline $6-12$ & 3 & 30 & 6 & 27 & \\
\hline$>12$ & 1 & 10 & 1 & 4 & \\
\hline Marital status & & & & & 0.36 \\
\hline Single & 17 & 61 & 25 & 60 & \\
\hline Married & 7 & 25 & 14 & 33 & \\
\hline Divorced & 4 & 14 & 2 & 5 & \\
\hline Widowed & 0 & 0 & 1 & 2 & \\
\hline
\end{tabular}


$64 \%)$ than in the abstinent users group $(n=14,33 \%)$ having legal problems (Table 2). Although non-significant $(p=0.55)$, there were also more active users $(n=17,94 \%)$ than past users $(n=11,85 \%)$ with heroin-related legal problems. However, most participants in both groups did not report pending criminal charges and convictions.

\section{Clinical data}

Table 2. Forensic data of active heroin users v. abstinent users during the four years after admission for heroin detoxification at the Opioid Doxification Unit at Stikland Hospital

\begin{tabular}{|c|c|c|c|c|c|}
\hline & \multicolumn{2}{|c|}{ Active users } & \multicolumn{2}{|c|}{ Abstinent users } & \multirow[b]{2}{*}{$p$-value } \\
\hline & $n$ & $\%$ & $n$ & $\%$ & \\
\hline Legal problems & & & & & $0.03^{*}$ \\
\hline Yes & 18 & 64 & 14 & 33 & \\
\hline No & 10 & 36 & 28 & 67 & \\
\hline Charges pending & & & & & 0.23 \\
\hline Yes & 3 & 17 & 0 & 0 & \\
\hline No & 15 & 83 & 14 & 100 & \\
\hline Convictions & & & & & 0.38 \\
\hline Yes & 7 & 39 & 5 & 36 & \\
\hline No & 11 & 61 & 9 & 64 & \\
\hline Heroin related & & & & & 0.55 \\
\hline Yes & 17 & 94 & 11 & 85 & \\
\hline No & 1 & 6 & 2 & 15 & \\
\hline
\end{tabular}

Table 3. Clinical data of active heroin users v. abstinent users during the 4 years after admission for heroin detoxification at the Opioid Detoxification Unit at Stikland Hospital

\begin{tabular}{|c|c|c|c|c|c|}
\hline & \multicolumn{2}{|c|}{ Active users } & \multicolumn{2}{|c|}{ Abstinent users } & \multirow[b]{2}{*}{$p$-value } \\
\hline & $n$ & $\%$ & $n$ & $\%$ & \\
\hline Frequency of use per day & & & & & 0.74 \\
\hline 1 & 3 & 11 & - & - & \\
\hline 4 & 3 & 11 & - & - & \\
\hline 5 & 15 & 53 & - & - & \\
\hline 10 & 7 & 25 & - & - & \\
\hline Mode of administration & & & & & 0.26 \\
\hline Inhalation & 28 & 100 & 39 & 93 & \\
\hline Injection & 0 & 0 & 3 & 7 & \\
\hline Health problems & & & & & 0.67 \\
\hline Yes & 3 & 11 & 3 & 7 & \\
\hline No & 25 & 89 & 39 & 93 & \\
\hline Psychiatric problems & & & & & 1.00 \\
\hline Yes & 3 & 11 & 5 & 12 & \\
\hline No & 25 & 89 & 37 & 88 & \\
\hline Type of psychiatric disorder & & & & & 0.64 \\
\hline Mood & 2 & 67 & 2 & 40 & \\
\hline Psychosis & 0 & 0 & 1 & 20 & \\
\hline Other & 1 & 33 & 2 & 40 & \\
\hline
\end{tabular}

There was no significant difference between abstinent and active users for frequency of use, mode of administration, health and self-reported psychiatric problems or type of psychiatric disorders over the past 4 years (Table 3$)$. Most active users $(n=15,54 \%)$ used heroin five times per day, with inhalation the most prevalent mode of administration in both active and abstinent users. Active users $(n=2$, $67 \%)$ also had a higher rate of mood disorders than abstinent users $(n=2,40 \%)$; however, most participants in both groups did not report health or psychiatric problems over the past 4 years.

\section{Treatment data}

The largest proportion $(n=25)$ of participants in both groups had been admitted and completed detoxification twice (Table 4). There was a significant $(p=0.04)$ difference in the longest period of abstinence between active and abstinent users, with more participants in the currently abstinent group $(n=24,62 \%)$ being abstinent for $\geq 18$ months than in active users $(n=8,31 \%)$. Although non-significant, there were more abstinent $(n=25$, $59 \%)$ than active users $(n=13,46 \%)$ with an abstinence period of $<3$ months. Furthermore, there was a significant $(p=0.02)$ difference in social support structures between active and abstinent users, with more participants in the currently abstinent group $(n=42,100 \%)$ having social support structures than active users $(n=24,86 \%)$. The majority of patients $(n=38,54 \%)$ relapsed within 3 months after index detoxification and rehabilitation. There was no significant difference between the groups for number of admissions, period of abstinence, readmission, private detoxification, rehabilitation after initial admission, type of rehabilitation, length of rehabilitation and for whether or not detoxification was completed.

\section{Discussion}

The objective of the study was to assess the outcome in heroin users 4 years after detoxification at the Opioid Detoxification Unit by specifically comparing the demographic, forensic, clinical and treatment data of active heroin users v. abstinent users.

Interestingly, the results showed that $55 \%$ of the interviewed sample was abstinent 4 years after the index admission to the Opioid Detoxification Unit. This finding reflects abstinence rates reported by other studies. The NTORS reported a $49 \%$ abstinence rate after 4 - 5 years of residential treatment and a $57 \%$ abstinence rate with maintenance programmes. ${ }^{[9]}$ The DATOS reported a reduction from $89 \%$ to $28 \%$ in weekly or more frequent heroin use 5 years after treatment. ${ }^{[5]}$ It should, however, be noted that the NTORS and DATOS studies included four different types of treatment modalities as opposed to only detoxification and relapse prevention via rehabilitation. Furthermore, these studies included larger prospective cohorts with moderate attrition rates (DATOS $20 \%$, NTORS $24 \%$ ), compared with the large number of untraceable participants lost to follow-up in the current retrospective report (49\%). The high number of currently abstinent users should therefore be interpreted with caution, as these individuals are often more likely to be contactable in contrast to active users for various social reasons. Alternatively, the high number of abstinent users could be related to difficulties in maintaining addiction as SA substance users do not qualify for state grants. Furthermore, one- 
Table 4. Treatment data of active heroin users v. abstinent users during the 4 years after admission for heroin detoxification at the Opioid Detoxification Unit at Stikland Hospital

\begin{tabular}{|c|c|c|c|c|c|}
\hline & \multicolumn{2}{|c|}{ Active users } & \multicolumn{2}{|c|}{ Abstinent users } & \multirow[b]{2}{*}{$p$-value } \\
\hline & $n$ & $\%$ & $n$ & $\%$ & \\
\hline Total admissions & & & & & 0.55 \\
\hline 1 & 3 & 10 & 10 & 25 & \\
\hline 2 & 13 & 43 & 12 & 30 & \\
\hline 3 & 3 & 10 & 3 & 7.5 & \\
\hline 4 & 3 & 10 & 3 & 7.5 & \\
\hline 5 & 2 & 7 & 3 & 7.5 & \\
\hline 6 & 4 & 14 & 7 & 17.5 & \\
\hline 7 & 1 & 3 & 2 & 5 & \\
\hline 10 & 1 & 3 & 0 & 0 & \\
\hline Detox completed & & & & & 0.73 \\
\hline Yes & 25 & 89 & 36 & 86 & \\
\hline No & 3 & 11 & 6 & 14 & \\
\hline
\end{tabular}

after detox, months

$\begin{array}{lllll}<3 & 13 & 46 & 25 & 59 \\ 3-5 & 5 & 19 & 7 & 17 \\ 6-11 & 2 & 7 & 3 & 7 \\ 12-17 & 2 & 7 & 0 & 0 \\ >18 & 6 & 21 & 7 & 17\end{array}$

Longest abstinence,

months

$0.04^{*}$

$3-5$

$6-11$

$12-17$

$>18$

Readmission

Yes

No

Private detoxification

Yes

No

Rehab after first

admission

Yes

No

Type of rehabilitation

$$
\text { Inpatient }
$$

Outpatient$$
17
$$

0.35

(1)

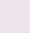

0.07

0.45

0.54

0.40

Continued ...

fifth of our abstinent group attributed abstinence to self-funded oral substitution pharmacotherapy.

For most participants, social support structures were reported to play the most important role in abstinence. There was also a significant difference between the groups for longest period of
Table 4. Treatment data of active heroin users $v$. abstinent users during the 4 years after admission for heroin detoxification at the Opioid Detoxification Unit at Stikland Hospital (Continued ...)

\begin{tabular}{llllll}
\hline & \multicolumn{2}{l}{ Active users } & \multicolumn{3}{l}{ Abstinent users } \\
\cline { 2 - 5 } & $n$ & $\%$ & $n$ & $\%$ & $p$-value \\
\hline
\end{tabular}

Length of time in rehabilitation programmes (weeks) 0.71

$\begin{array}{lllll}1 & 1 & 4 & 1 & 3 \\ 2 & 2 & 8 & 2 & 7 \\ 3 & 1 & 4 & 3 & 10 \\ 4 & 0 & 0 & 1 & 3 \\ 5 & 1 & 4 & 0 & 0 \\ 7 & 6 & 23 & 10 & 33 \\ 8 & 12 & 45 & 7 & 24 \\ 10 & 2 & 8 & 3 & 10 \\ 12 & 1 & 4 & 2 & 7 \\ 14 & 0 & 0 & 1 & 3 \\ \text { Support structures } & & & & \\ \text { Yes } & 24 & 86 & 42 & 100 \\ \text { No } & 4 & 14 & 0 & 0 \\ * 0<0.05, \text { Pearson's } x^{2} \text { test, Fisher's exact two-tailed test } & \end{array}$

abstinence, with more participants in the past user group with a period of abstinence $>18$ months, compared with active users. We are not aware of previous studies addressing duration of abstinence and its associated factors following detoxification and rehabilitation; this suggests the need for further research in this area. Nevertheless, the significant effect of social support structures on abstinence is similarly reflected in other reports. For example, Flynn et al. ${ }^{[10]}$ reported that $28 \%$ of NTORS patients in recovery 5 years following outpatient methadone maintenance programmes relied primarily upon personal motivation, treatment experiences, religion/spirituality, family and their job/career. Patients in this study placed particular value on social support from family and close friends. A study conducted by Ellis et al. ${ }^{[11]}$ also concluded that positive family activities during the postdischarge period significantly decreased the likelihood of relapse, while negative family activities such as fights and drug use or criminal activity by friends increased the likelihood of relapse. A study conducted by Best et al..$^{[12]}$ confirmed that while achieving abstinence is possible for chronic opiate users, the path to sustained abstinence is complex and often reliant upon external social support systems.

There was no association between current abstinence (as defined above) and length of stay in rehabilitation. International large cohort studies such as DARP, TOPS, DATOS and NTORS all indicate better outcomes associated with a $\geq 3$-month duration of treatment. ${ }^{[4,9]}$ It should, however, be noted that the duration of treatment for in- or outpatients did not exceed 12 weeks as governmentfunded treatment programmes are usually 6 - 8 weeks in duration in our current setting. Only one of the 70 respondents had a treatment programme of 14 weeks' duration, making it difficult to comment on this finding.

A total of $54 \%(n=38)$ of participants relapsed within the first 3 months after index detoxification and rehabilitation. Similarly, studies such as NTORS reported that $60 \%$ of patients relapsed within 90 days 
after treatment. ${ }^{[9]}$ This is worrying, as legal problems were significantly more frequent in active users than abstinent users. Legal problems were based on self-reports and included not only pending charges and convictions, but also criminal activities not reported to the police or correctional services and arrest for acquisition crimes without charges or convictions.

Nevertheless, the higher incidence of overall legal problems in active users is worrying, as criminal activity among active users may be further compounded by the high rates of heroin use and unemployment in SA. ${ }^{[13]}$ Likewise, more active users (64\%) tended to be unemployed than abstinent users. Unemployment is a possible confounding factor for increased criminal activity in active users who were possibly involved in criminal activity other than acquisition crimes to provide for other needs. Other possible confounders include criminal activity related to the use of other substances unrelated to heroin. The details pertaining to the use of substances other than heroin were not explored in this study and need to be further explored.

Many international studies confirm that drug use increases the incidence of criminal activity. ${ }^{[4,14]}$ Findings from a recent study by Sokya et al. ${ }^{[15]}$ show a significant rate of criminal activity and convictions in patients entering opioid-substitution treatment and a decrease in criminal activities over time. Gossop et al. ${ }^{[5]}$ also showed that longer periods of stay in methadone treatment were linked to greater reductions in both heroin use and criminal activity.

The biggest limitation of this study was the large number of untraceable cases that may have biased the results. A further limitation was the relatively small sample size and the use of selfreport questionnaires. Under self-reporting conditions, there is potential response distortion not only of each measure, but also of correlations between measures. Self-reported answers may be exaggerated, respondents may be too embarrassed to reveal private details or forget pertinent details, while various other biases may also affect the results, such as the respondent's feelings at the time of completion. Furthermore, and as with all studies relying on voluntary participation, results may be biased by a lack of respondents and if there are systematic differences between those who respond and those who do not respond. Nevertheless, this is the first descriptive study in SA comparing outcome data between active and abstinent users 4 years following detoxification for heroin dependence.

\section{Conclusion}

The findings of this study are consistent with other outcome studies showing a reduction in legal problems following treatment and the pivotal role of social support structures in abstinence. Future research should assess the impact of interventions such as post-discharge social support programmes on criminality and heroin use in those who relapse following treatment.

Acknowledgments. Funding from the Harry Crossley foundation is hereby acknowledged.

\section{References}

1. Ramlagan S, Peltzer K, Matseke G. Epidemiology of drug abuse treatment in South Africa. South African Journal of Psychiatry 2010:16(2):40-49.

2. Dada S, Plüddemann A, Parry C, Bhana A, Vawda M, Fourie D. Alcohol and Drug Abuse Trends: January - June 2011 (Phase 30). Cape Town: South African Community Epidemiology Network on Drug Use (SACENDU), 2011. http://www.sahealthinfo.org/admodule/sacendu.htm (accessed 21 June 2012).

3. World Health Organization. Guidelines for the Psychosocially Assisted Pharmacological Treatment of Opioid Dependence. Geneva: Word Health Organization Press, 2009. http:// www.who.int/substance abuse/publications/opioid dependence guidelines.pdf (accessed 24 June 2013).

4. Hubbard RL, Craddock SG, Anderson J. Overview of five-year follow-up outcomes in the drug abuse treatment outcome studies (DATOS). J Subst Abuse Treat 2003;25(3):125-134. [http:// dx.doi.org/10.1016/S0740-5472(03)00130-2]

5. Gossop M, Trakada K, Stewart D, Witton J. Reduction in criminal conviction after addiction treatment: 5-year follow up. Drug Alcohol Depend 2005;79(3):295-302. [http://dx.doi. org/10.1016/j.drugalcdep.2005.01.023]

6. Teesson M, Mills K, Ross J, Darke S, Williamson A, Havard A. The impact of treatment on 3 years' outcome for heroin dependence: Findings from the Australian Treatment Outcome Study (ATOS). Addiction 2007;103(1):80-88. [http://dx.doi.org/10.1111/j.13600443.2007.02029.x]

7. Termorshuizen F, Krol A, Prins M, van Ameijden EJC. Long-term outcomes of chronic drug use: The Amsterdam cohort study among drug users. Am J Epidemiol 2005;161(3):271-279. [http://dx.doi.org/10.1093/aje/kwi035]

8. Gandhi DH, Jaffe JH, McNary S, Kavanagh GJ, Hayes M, Currens M. Short-term outcomes after brief ambulatory opioid detoxification and buprenorphine in young heroin users Addiction 2003;98(4):453-462. [http://dx.doi.org/10.1046/j.1360-0443.2003.00334.x]

9. Gossop M, Marsden J, Stewart D, Kidd T. The National Treatment Outcome Research Study (NTORS): 4-5 year follow up results. Addiction 2003;98(3):291-303. [http://dx.doi. org/10.1046/j.1360-0443.2003.00296.x

10. Flynn PM, Joe GW, Broome KM, Simpson DD, Brown BS. Recovery from opioid addiction in DATOS. J Subst Abuse Treat 2003;25(3):177-186. [http://dx.doi.org/10.1016/S07405472(03)00125-9]

11. Ellis B, Bernichon T, Yu P, Roberts T, Herrell JM. Effect of social support on substance abuse relapse in a residential treatment setting for women. Eval Program Plann 2004;27(2):213-221. [http://dx.doi.org/10.1016/j.evalprogplan.2004.01.011]

12. Best DW, Ghufran S, Day E, Ray R, Loaring J. Breaking the habit: A retrospective analysis of desistance factors among formerly problematic heroin users. Drug Alcohol Rev 2008;27(6):619-624. [http://dx.doi.org/10.1080/09595230802392808]

13. Statistics South Africa. Work and Labour Force, Formal Sector Employment. http://www. statssa.gov.za/default.asp (accessed 19 July 2012).

14. Martin SS, O'Connell DJ, Paternoster R, Bachman RD. The long and winding road to desistance from crime for drug-involved offenders: The long-term influence of TC Treatment on re-arrest. J Drug Issues 2011;41(2):179-196. [http://dx.doi. org/10.1177/002204261104100202]

15. Sokya M, Träder A, Klotsche J, et al. Criminal behaviour in opioid-dependent patients before and during maintenance therapy: 6-year follow-up of a nationally representative cohort sample. J Forensic Sci 2012;57(6):1524-1530. [http://dx.doi.org/10.1111/j.15564029.2012.02234.x] 